\title{
Preliminary Investigation of the Microstructure and Mechanical Behaviour of 2024 Aluminium Alloy Friction Spot Welds*1
}

\author{
Sergio T. Amancio-Filho ${ }^{1,2}$, Ana P. C. Camillo ${ }^{3, * 2}$, Luciano Bergmann ${ }^{1}$, \\ Jorge F. dos Santos ${ }^{1}$, Sebastião E. Kury ${ }^{3}$ and Nelson G. A. Machado ${ }^{3}$ \\ ${ }^{1}$ Helmholtz-Zentrum Geesthacht, Institute of Materials Research, Materials Mechanics, Solid State Joining Processes, \\ Max-Planck-St. 1, D-21502 Geesthacht, Germany \\ ${ }^{2}$ Helmholtz-Zentrum Geesthacht, Institute of Materials Research, Materials Mechanics, Advanced Polymer-Metal Hybrid Structures, \\ Max-Planck-St. 1, D-21502 Geesthacht, Germany \\ ${ }^{3}$ Federal University of Sao Carlos (UFSCar), Departamento de Engenharia de Materials (DEMa), \\ Rodovia Washington Luiz km 235, 13565-905 São Carlos-SP, Brazil
}

Friction Spot Welding (FSpW) is a new solid-state joining process able to produce similar and dissimilar overlap connections in different classes of materials. Advantages of this new technique are: short production cycles, high performance joints, absence of filler materials and good surface finishing supported by material refilling in the spot area. Although few authors have addressed the microstructural and mechanical behavior of friction spot welds of Aluminum alloys, there is still a lack of a systematic evaluation on the process-properties relationship. In this work the AA2024-T3 alloy (rolled sheets) was selected for the welding procedure. Design of Experiment and Analyses of Variance techniques were employed to evaluate joint shear strength under static loading. Sound joints with elevated shear strength were achieved and the influence of the main process parameters on joint strength evaluated. [doi:10.2320/matertrans.L-MZ201126]

(Received October 2, 2010; Accepted February 2, 2011; Published May 1, 2011)

Keywords: aluminum alloys, friction spot welding, friction stir welding, full factorial design, friction welding

\section{Introduction}

Friction Spot Welding (FSpW) is a new solid-state joining process developed and patented by GKSS Forschungszentrum $\mathrm{GmbH}^{1)}$ to weld lightweight metals and thermoplastics. The principles of the technique are presented in Fig. 1. There are two process variants, the Sleeve-Plunge (SP) and the PinPlunge (PP) operation modus. ${ }^{2)}$ In both variants the joining partners are initially fixed in the welding machine (Fig. 1(A)). Sleeve and pin start to rotate in the same direction under a pre-set speed. Following that, either the sleeve (in the SP modus, Fig. 1(B)) or the pin (in the PP modus, Fig. 1(E)) is forced against the upper joining partner generating frictional heat. A volume of plasticized metal is formed around the rotating tool piece. In the SP variant (Fig. 1(B)), the pin is concomitantly retracted during sleeve plunging; it creates a cavity to where the plasticized metal will flow in. When a pre-determine plunge depth is reached, the sleeve is retracted backwards and the pin towards to their original position (Fig. 1(C)); this will force the plasticized metal entrapped in the formed cavity to refill the key-hole left by the sleeve. By the end of the welding cycle the tool is retracted and the joint formed (Fig. 1(D)).

In the PP modus (Fig. 1(E)) the tool cavity is resultant from the retraction of sleeve while the pin is inserted into the joining partners. The other steps are equal to the SP modus. Welds obtained through the SP modus are larger then the PP modus welds, leading to stronger joints. ${ }^{3)}$ On the other hand the Pin-plunge variant is easier to perform since it demands less power associated with lower frictional forces. $^{4)}$

\footnotetext{
${ }^{* 1}$ The Paper Contains Partial Overlap with the ICAA12 Proceedings by USB under the Permission of the Editorial Committee.

${ }^{* 2}$ Graduate Student, Federal University of Sao Carlos (UFSCar)
}

The FSpW is able to produce similar and dissimilar overlap connections in different classes of materials, such as aluminum, magnesium, steel and thermoplastics. The FSpW (also known as Refill Friction Stir Spot Welding) was conceived aiming to avoid or decrease some limitations usually observed at other spot-like joining technologies, such as found at FSSW, such as weight penalty, difficult of automation, requirement for sealants and corrosion problems in mechanical fastening ${ }^{5-8)}$ and the presence of a key-hole a limitation found in the Friction Stir Spot Welding. Other advantages of this solid-state welding technology are absence of defects associated with conventional fusion welding techniques such as Resistance Spot (RSW) and Laser Spot Welding (LSW). For instance the fusion welding of high strength aluminum alloys is limited by the presence of the oxide/hydroxide which has higher melting temperatures and lower thermal conductivity than the metal substrate. In this case higher thermal energies are required to break up the oxide layer to melt down the substrate; this can induce alloy elements evaporation leading to properties degradation. Furthermore hydrogen cracking can take place during welding consolidation. ${ }^{2)}$ FSpW also consumes less energy in comparison to other fusion welding processes. Moreover, friction spot welds have good surface finishing (absence of key-holes or large weld beads) resulting in improved mechanical behavior. ${ }^{9)}$

Design of Experiments (DOE) is a powerful statistical tool often in industrial process optimization and analysis. The most popular DOE approaches used in welding were addressed by Benyounis and Olabi. ${ }^{10)}$ Designs commonly used are the Central Composite Design (CCD), the Response Surface Method (RSM), the Full-Factorial Design (FFD) and the Taguchi Method.

The FFD is frequently selected for welding processes due to its short computational time regular experimental domain, 


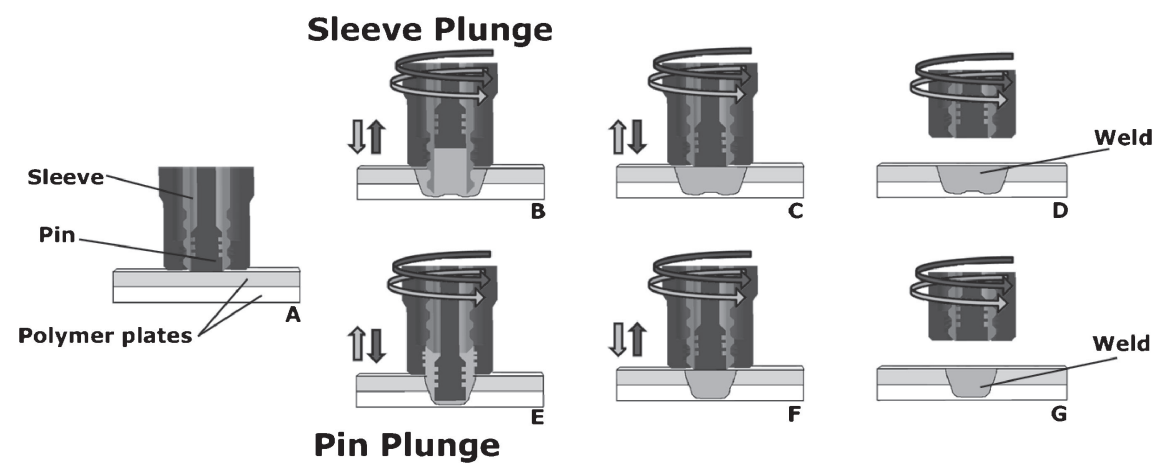

Fig. 1 Scheme of the FSpW process: (A) to (D) the Sleeve-Plunge Variant and (E) to (G) the Pin-Plunge Variant.

the possibility of modeling responses (weld properties), high accuracy and easy understanding. The FFD is most adequate in situations where a reduced number of parameters can be selected. In welding this scenario can be found when the initial trials were able to allow the identification of the most important process parameters, such as for $\mathrm{FSpW}$. Casalino ${ }^{11)}$ successfully applied a FFD to analyze the influence of processing on the weld penetration in MIG- $\mathrm{CO}_{2}$ welds. Olabi et al. ${ }^{12)}$ used a $3^{\mathrm{k}}$ FFD, RSM and Taguchi designs in order to minimize the residual stresses in laser welded structures. Lakshminarayanan and Balasubramanian ${ }^{13)}$ applied Taguchi designs in order to investigate the influence of rotational speed, welding speed and axial force on the tensile properties of Al-Zn-Mg alloys. Hunt et al. ${ }^{14)}$ were able to design a L-18 Taguchi orthogonal array model for the investigation of the friction stir stitch welded (an alternative spot welding process based on the FSW) AA 6022-T4 alloy. They investigated the influence of 8 different factors on the weld shear strength. Their resulted pointed out that $R S, J T$ and plunge depth had a strong influence in the weld performace. Oberembt et al. ${ }^{15}$ ) carried out a preliminary statistical investigation of the PPmodus FSpW in $\mathrm{Al} 6061$ alloys based on a $2^{\mathrm{k}-1}$ Half-Fraction Factorial. They investigated the influence of 7 different process parameters (factors) in the lap shear tensile weld strength and in the metallurgical changes during welding. They concluded that the welding parameters mostly influencing the weld strength are plunge depth, pin retract rate and dwell time. From our current knowledge there are no studies published addressing the SP-modus of the FSpW.

The aim of the present work was to investigate the influence of the rotational speed and joining time on the strength of overlap welds on AA 2024-T3 alloy produced by Friction Spot Welding. A $3^{\mathrm{k}}$ Full Factorial Design was selected for this purpose and the average lap shear strength of the joints taken as the main response. Analysis of variance was performed to evaluate the statistical confidence of the designed model. Finally examples of the microstructural changes and failure mechanisms of the spot welds were discussed in order to illustrate the main characteristics of the joints investigated in this study.

\section{Materials and Methods}

\subsection{AA 2024-T3 alloy}

$2 \mathrm{~mm}$ rolled sheets were used to produce overlap joints for lap shear testing. AA 2024-T3 alloy is a ternary $\mathrm{Al}-\mathrm{Cu}-\mathrm{Mg}$

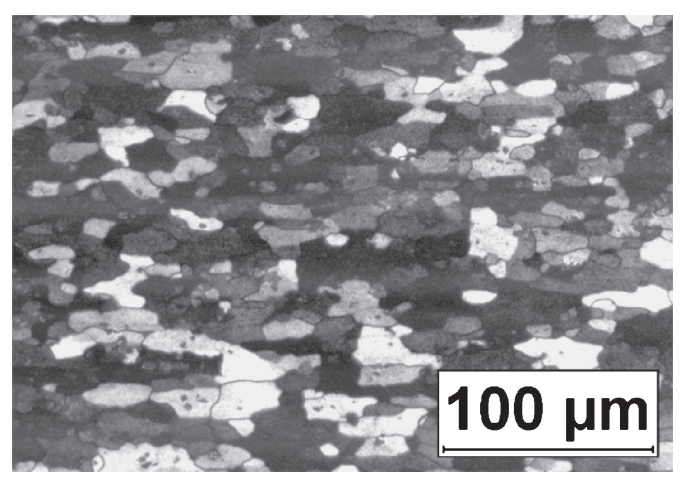

Fig. 2 Microstructural aspects of the as-received AA 2024-T3 alloy base material (Barker, 200X).

alloy, normally used in fuselages and other aircraft structures. ${ }^{16)}$ This alloy exhibits poor weldability by fusion processes but has been shown to be successfully welded by FSpW. ${ }^{2)}$ The rolled sheets exhibit medium to good stress corrosion resistance and good tensile strength $(425 \mathrm{MPa}){ }^{16,17)}$ Figure 2 presents the microstructure of the AA 2024-T3 alloy parallel to the rolling direction.

\subsection{Microstructural analysis and mechanical testing}

Metallographic sections were extracted from the center of the spot weld in the rolling direction. Specimens were embedded in epoxy resin and prepared through metallographic specimen preparation procedures. Polished specimens were etched with Kroll reagent $\left(96 \mathrm{~mL}\right.$ distilled $\mathrm{H}_{2} \mathrm{O}$, $6 \mathrm{~mL} \mathrm{HNO}_{3}$ and $2 \mathrm{~mL} \mathrm{HF}$ ) for macrostructural characterization and with Barker $\left(200 \mathrm{~mL}\right.$ distilled $\mathrm{H}_{2} \mathrm{O}, 5 \mathrm{~g}$ fluoboric acid 35\%) for microstructural analysis under polarized reflective light.

Tensile tests of base material and lap shear testing of overlap joints were carried out in a universal testing machine equipped with a $100 \mathrm{kN}$ load cell, using a traverse speed of $2 \mathrm{~mm} / \mathrm{min}$ at room temperature. Specimen geometry for the tensile testing of base material was in accordance with EN $895^{18)}$ and for lap shear tensile testing of welds the DIN EN ISO 14273 standard $^{19)}$ (see Fig. 3).

\subsection{Welding procedure and design of experiments approach}

Overlap spot welds were produced in a commercially available friction spot welding equipment (RPS 100, HarmsWende, Germany). Threaded FSpW tools (fabricated out of 


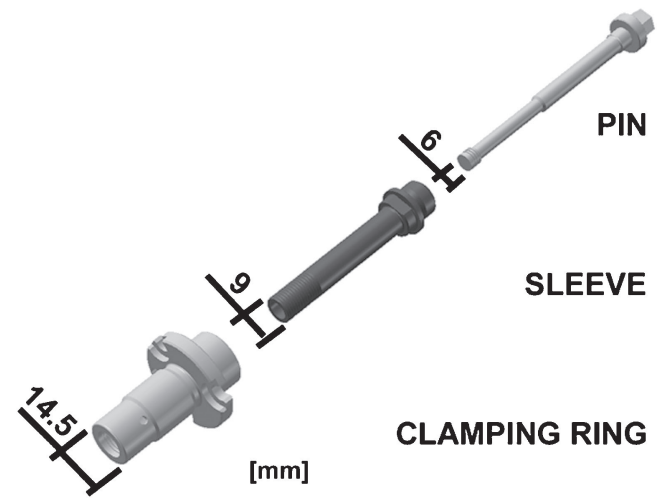

Fig. 3 Scheme of the FSpW-tools used in this work.

Table $1 \quad 3^{2}$-full factorial design of experiments used to evaluate FSpW shear strength.

\begin{tabular}{cccccccccc}
\hline Weld & $\mathbf{1}$ & $\mathbf{2}$ & $\mathbf{3}$ & $\mathbf{4}$ & $\mathbf{5}$ & $\mathbf{6}$ & $\mathbf{7}$ & $\mathbf{8}$ & $\mathbf{9}$ \\
\hline $\boldsymbol{R} \boldsymbol{S}[\mathbf{r p m}]$ & 1900 & 1900 & 1900 & 2400 & 2400 & 2400 & 2900 & 2900 & 2900 \\
\hline $\boldsymbol{J} \boldsymbol{T}[\mathbf{s}]$ & 4.8 & 5.8 & 6.8 & 4.8 & 5.8 & 6.8 & 4.8 & 5.8 & 6.8 \\
\hline
\end{tabular}

UHB Marax ESR steel, material DIN 1.6358, see Fig. 3) were pre-heated to $150^{\circ} \mathrm{C}$ prior to weld, a procedure adopted in order to try to approach real production conditions. Optimized welding set-up pressure of 2.8 bar, sleeve plunge of $2.5 \mathrm{~mm}(0.5 \mathrm{~mm}$ plunging in the inferior plate $)$ were selected from a preliminary work ${ }^{20)}$ and kept constant, while varying the rotation speed (1900, 2400 and $2900 \mathrm{rpm})$ and joining time $(4.8,5.8$ and $6.8 \mathrm{~s})$. Dwell time was not used in this study.

A three-level full-factorial design of experiments $\left(3^{\mathrm{k}}\right)$ with two factors ( $R S$ and $J T$ ) was selected for the evaluation of the Ultimate Lap Shear Strength (ULSS) of the weld, with three replicates. Table 1 summarizes the $3^{2}$-full factorial design used in this work.

\section{Results and Discussions}

\subsection{Microstructural features of AA 2024-T3 alloy over- lap joints}

The typical microstructure of a AA 2024-T3 alloy sound joint (1900 rpm, $4.8 \mathrm{~s}, 2.5 \mathrm{~mm}$ plunge) can be observed in Fig. 4. Figure 4(A) presents the cross-section of this joint prior to etching. Contrary to other works, such as by Tier et al. ${ }^{21)}$ and Silva et al. ${ }^{9)}$ overlap joints produced in this study did not present a well defined bond ligament, typical of aluminum friction spot connections. This suggests the presence of an improved material mixing observed in the range of the studied welding parameters.

The transition between the Thermo-Mechanically Affected Zone, TMAZ (characterized by a 90 degree rotation of the base material grains due to tool stirring ${ }^{22)}$ ) and the Stir Zone, SZ (the region in the center of the spot with fine dynamic recrystallized grains, originated by the high shear rates and process temperature ${ }^{22)}$ ) can be observed in Fig. 4(B) and 4(D). From Fig. 4(C) the absence of refilling defects and a sharp transition between the very fine grain structure of the Stir Zone and the partially recrystallized grains of the TMAZ can be seen by optical contrast (non-etched specimen). The presence of the so-called "hook" characterized by the deviation of the non-welded interface line is presented in Fig. 4(E). The hook is usually characterized by an upward shifting of the interface line in the TMAZ followed by a downward shifting in the SZ occasioned $b$ the re-filling of the plasticized material in the spot weld. In the current study joint hook presents an accentuated downward shifting pattern, probably due to an improved material mixing related to the optimized profile of the tools selected in this work. Part of the bonding ligament line was reveled by etching and can be seen in Fig. 4(F) (indicated by a white arrow). This fact and the presence of very fine grains produced by dynamic recrystallization in the SZ (see Fig. 4(G)) additionally confirms that material mixing was improved by adequate processing temperatures and shear deformation rates.

Dynamic recrystallization is a typical metallurgical phenomena found in $\mathrm{FSpW}^{9}$ and other friction-based welding processes, such as friction stir welding ${ }^{23)}$ and friction stir spot welding of aluminum alloys. ${ }^{24)}$ Friction welded AA 2024 alloy can experiences dynamic recrystallization at process temperatures starting at about $50 \%$ of the alloy melting temperature $\left(502-638^{\circ} \mathrm{C}^{16,17)}\right)$ and high shear rates associated with rotational speeds varying from 500 to $2900 \mathrm{rpm} .^{9)}$ In order to avoid damage of the thermocouples, process temperatures were measured with $\phi 5 \mathrm{~mm}$ type $\mathrm{K}$ thermocouples inserted in the HAZ of the spot welds (at $16 \mathrm{~mm}$ from the spot center and placed into the upper plate at $1 \mathrm{~mm}$ from the top surface). Maximum temperature varied within 345$398^{\circ} \mathrm{C},{ }^{20)}$ which is approximately $50-60 \%$ of the melting point of the AA 2024 alloy. Therefore average temperature and shear deformation rates in the SZ were probably high enough to support dynamic recrystallization leading to grain refinement in comparison to the base material (compare Figs. 2 with 4(B) and 4(D)).

\subsection{Joint failure behavior under shear loading}

Two typical fracture behaviors observed in this study are present in Figs. 5 and 6. The first mechanism (Fig. 5) was described as the "through the weld" fracture (TW) by Allen et $a .^{24)}$ This mechanism is usually associated with catastrophic brittle fracture of the joint. Joint fails suddenly with crack path taking place through the SZ parallel to the overlap interface. In other types of spot welds ${ }^{24)}$ this fracture type is rejected because joint shear strength is normally low. In the case of the current joints, this sort of fracture has resulted in high strength and intermediate ductility (see Fig. 7). This was also observed by Rosendo. ${ }^{21)}$ Due to the imposed stress fields around the spot an annular crack (see black arrows in Fig. 5(B)) will nucleate in the region near to the beginning of the interface shifting of the hook (a region of moderate bonding strength) and propagate to center of the stir zone in a plan parallel to the plates' interface at the bonding ligament.

The second fracture mechanism observed is the "plug pullout with back plug" (PB) fracture type with the plug remaining partially connected to the upper plate ${ }^{24)}$ (Fig. 6). This is a typical failure modus found in sound aluminum friction spot joints. ${ }^{3)}$ Joint exhibiting this mechanism fails in a ductile manner prior to final fracture. Shear strength is high as well as the fracture toughness of the joint, which is 

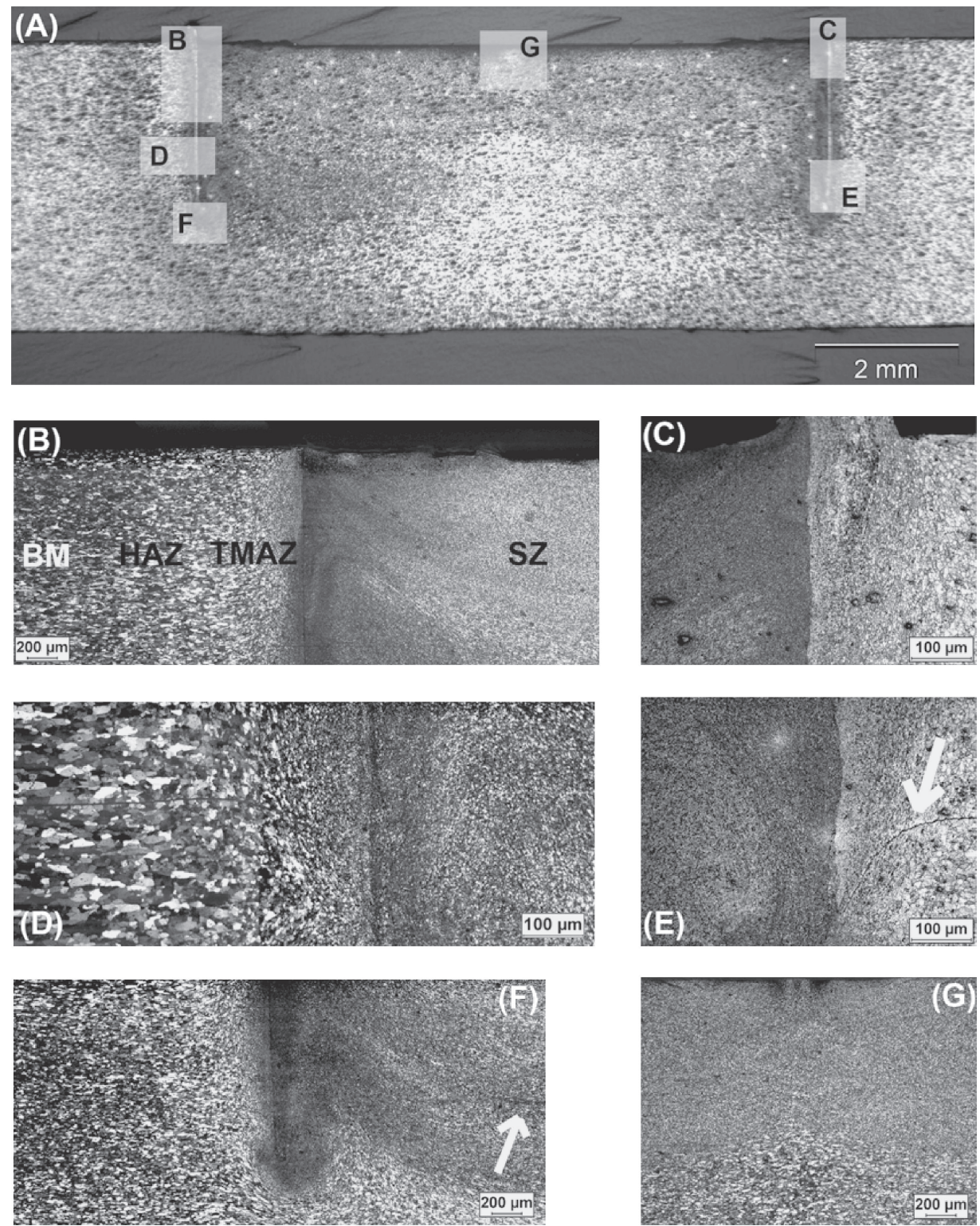

Fig. 4 Microstructure of a AA 2024-T3 alloy friction spot weld (1900 rpm, 4.8 s, 2,5 mm plunge). (A) Non-etched macrograph of the weld cross-section; (B) Region showing the transition between base material, Heat Affected Zone (HAZ), Thermo-Mechanically Affected Zone (TMAZ) and Stir Zone, (SZ) (Barker etchant); (C) Detail of the transition between stirred material in the SZ and in the TMAZ (nonetched); (D) Magnification showing the 90 degrees rotation of the grains in the TMAZ (Barker etchant); (E) Non-etched micrograph showing the downward shifting of the hook in the TMAZ (white arrow); (F) The bonding ligament in the SZ (white arrow) and (G) the very fine dynamic recrystallized grains in the SZ.
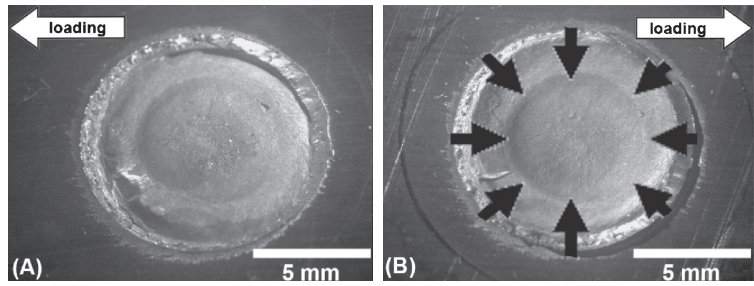

Fig. 5 Example of a tested lap shear specimen showing the "through the weld" fracture mechanism type: (A) the upper plate and (B) the lower plate; black arrows indicate the path of the annular crack. (weld conditions: $2900 \mathrm{rpm}, 5.8 \mathrm{~s}, 2.5 \mathrm{~mm}$ plunge).
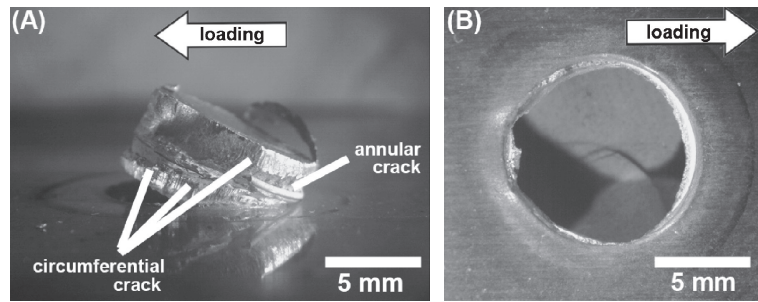

Fig. 6 Example of a tested lap shear specimen showing the "plug pullout with back plug" fracture mechanism with the plug remaining connected to the upper plate: (A) the plug at the upper plate and the annular/ circumferential cracks indicated by white lines. (B) the lower plate where final failure took place by circumferential cracking (weld conditions: $1900 \mathrm{rpm}, 4.8 \mathrm{~s}, 2.5 \mathrm{~mm}$ plunge). 


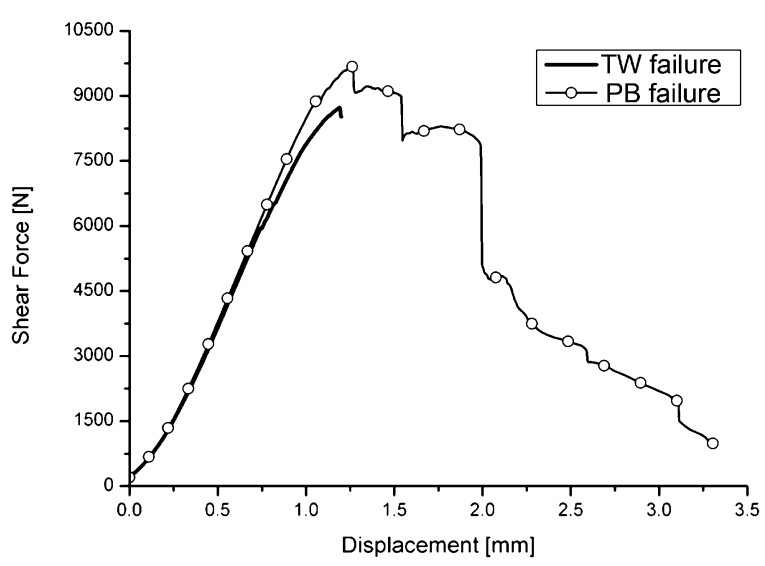

Fig. 7 Example of force vs. displacement curve observed during the lap shear testing of joints failing by TW and PB mechanisms. The curve for the TW specimens is correspondent to the joint in Fig. 5. The curve for the $\mathrm{PB}$ specimen is relative to the joint in Fig. 6.

characterized by a large area underneath the force versus displacement graph (Fig. 7). Annular cracks nucleate along with circumferential cracks usually at the TMAZ in the hook portion. However annular crack propagation does not follow the bonding ligament path as in the case of TW failure; overall bonding ligament strength in this case is high enough to induce the nucleation of the circumferential cracking, normally at the tip of the annular crack. Circumferential cracks will propagate in a perpendicular plan through the thickness of the plates (Fig. 6(A)). Final joint failure takes place around the spot as shown in Fig. 6(B). Both annular and circumferential cracks occur in regions subjected to tensile stresses. For a complete description of failures mechanisms in FSpW connections please refer to. ${ }^{22)}$

\subsection{Influence of the welding parameters on the joint strength}

The $3^{2}$-FFD was selected in this work for evaluating all interactions and main factors without aliasing concerns. Furthermore this study served as a base for the selection of optimized joints for a complementary investigation on the corrosion properties (to be published in a separate manuscript).

The Analysis of Variance for the general linear model designed in this work is given in Table 2 for an $\alpha=0.05$ (or an interval of confidence of 95\%). Low $p$-values $(p<0.05)$ and high $T$-values for the $R S$ and $J T$ as well as for the second grade interaction $R S^{*} J T$ indicate that the model is statistically coherent. This is additionally confirmed by the good correlation coefficient $R^{2}=0.98$. However $R S$ seems to have the lowest influence on the response ULSS ( $p$-value is near to the $p=0.05)$. This can be observed by the contribution of the $R S$ of about $1.2 \%$ in comparison the contribution of the model error of about $2.2 \%$.

The main effect for the mean ULSS is presented in Fig. 8. If on one hand the reduced contribution of the $R S$ on ULSS is represented by the flatter curve profile (Fig. 8(A)), on the other hand the importance of the $J T$ to the ULSS is confirmed once more by the steep increase in ULSS with JT (Fig. 8(B)). Although the effect of the $R S$ on joint strength is not remarkable, plots of Fig. 8 suggests increasing both factors in
Table 2 Analysis of variance for the response ultimate lap shear strength.

\begin{tabular}{ccccccc}
\hline Source & SS & df & MS & F & p & Contrib. [\%] \\
\hline Rotational Speed [rpm] & 0.6330 & 2 & 0.3165 & 4.726 & 0.022 & $1.17 \%$ \\
\hline Joining Time [s] & 38.4 & 2 & 19.2 & 286.727 & 0.000 & $70.72 \%$ \\
\hline AB & 14.1 & 4 & 3.5 & 52.481 & 0.000 & $25.89 \%$ \\
\hline Error & 1.205 & 18 & 0.067 & & & $2.22 \%$ \\
\hline Total & 54.299 & 26 & & & & \\
\hline
\end{tabular}

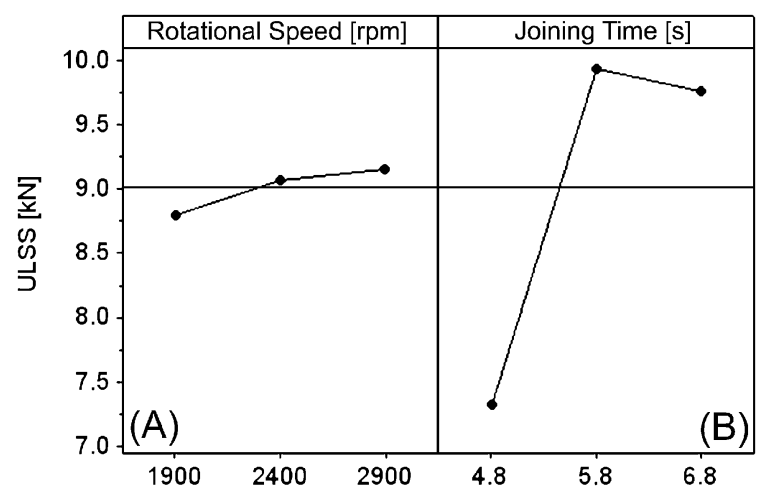

Fig. 8 Main effect plots of rotational speed (A) and joining time (B) on the mean ultimate lap shear strength (ULSS). The horizontal reference line is referred to the average value of all observations in all factor levels in the experiment (avg. ULSS $=9.0 \mathrm{kN}$ ). The points in $(\mathrm{A})$ and $(\mathrm{B})$ are the means of ULSS at the various levels of each factor (calculated from Table 3).

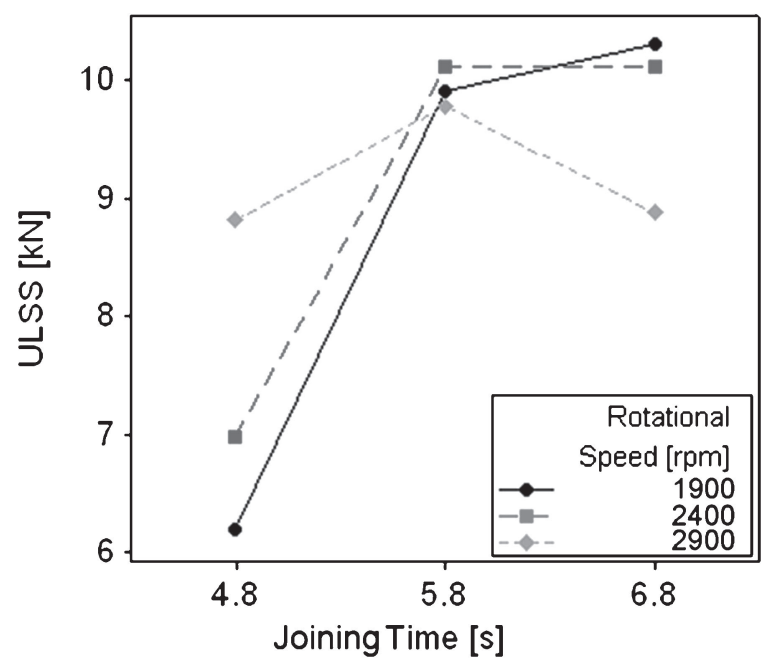

Fig. 9 Effects of the interaction between rotational speed and joining time on the mean ultimate lap shear strength (ULSS).

order to achieve stronger joints in the investigated range of welding parameters. However increases in $J T$ at values above intermediate levels $(J T>5.8 \mathrm{~s})$ seems to be prejudicial to joint strength.

The first order interaction between $R S$ and $J T$ in terms of the mean ULSS is shown in Fig. 9. Since the curves for the $1900 \mathrm{rpm}$ and $2400 \mathrm{rpm}$ are quite parallel those plots do not show any remarkable interaction within 4.8 to $6.8 \mathrm{~s}$. Nevertheless $R S$ and $J T$ appears to interact at higher values of $R S$ (the curve for $2900 \mathrm{rpm}$ substantially deviates from the behavior of 1900 and $2400 \mathrm{rpm}$ at 4.8 and $6.8 \mathrm{~s}$ ). It is 
Table 3 Summary of the $3 \mathrm{k}$-full factorial design conditions and their average ultimate lap shear strengths.

\begin{tabular}{ccccc}
\hline Condition & $\begin{array}{c}\text { Rotational } \\
\text { Speed [rpm] }\end{array}$ & $\begin{array}{c}\text { Joining Time } \\
{[\mathbf{s}]}\end{array}$ & $\begin{array}{c}\text { Average ULSS } \\
{[\mathbf{k N}]}\end{array}$ & $\begin{array}{c}\text { Standard } \\
\text { Deviation [kN] }\end{array}$ \\
\hline 1 & 1900 & 4.8 & 6.2 & 0.1 \\
\hline 2 & 1900 & 5.8 & 9.9 & 0.2 \\
\hline 3 & 1900 & 6.8 & 10.3 & 0.1 \\
\hline 4 & 2400 & 4.8 & 7.0 & 0.1 \\
\hline 5 & 2400 & 5.8 & 10.1 & 0.2 \\
\hline 6 & 2400 & 6.8 & 10.1 & 0.1 \\
\hline 7 & 2900 & 4.8 & 8.8 & 0.1 \\
\hline 8 & 2900 & 5.8 & 9.8 & 0.6 \\
\hline 9 & 2900 & 6.8 & 8.9 & 0.3 \\
\hline
\end{tabular}

probably associated with the changes in the heat input regime related to variations in the frictional heating. It can be better understood for the lower and upper $J T$-values. At $4.8 \mathrm{~s}$ an increases in $R S$ will lead to higher values in ULSS because of more heat is being generate by friction; this was observed by $\mathrm{Su}$ et $a .^{25)}$ in friction stir spot welding, in which heat generation is similar to the FSpW. They modeled that $R S$, Torque and Joining Time are directly proportional to heat input. In this way larger welds can be created with the selection of larger rotation speeds at constant time and joining forces. At larger $J T$-values, heating efficiency is already large; further increases in $R S$ can lead to a decrease in Torque associated with a decrease in the plasticized material viscosity (occasioned by the increase in temperature). Therefore a drop in the heating generation efficiency can take place due to the slipping of the tool and the plasticized metal. This is a common phenomenon observed in friction stir welding known sometimes as the slip/stick transition. ${ }^{26)}$ Decreases in heat generation will lead to smaller welded areas and consequently weaker welds as it was observed for increases in $R S$ at the highest $J T$-values $(6.8 \mathrm{~s})$. The geometrical changes of the investigated spot welds were discussed elsewhere. ${ }^{27)}$ Finally, Figs. 8 and 9 indicate that the highest weld strengths with can be achieved when working with intermediate $R S$ and $J T$.

Table 3 presents the average experimental results for the average ULSS in this study. The ULSS varied from about $6 \mathrm{kN}$ (Condition 1-1900 rpm and $4.8 \mathrm{~s}$ ) to $10 \mathrm{kN}$ (Condition 6-2400 rpm and $6.8 \mathrm{~s}$ ) with a standard deviation of $0.1 \mathrm{kN}$. The highest standard deviation values of 0.6 and $0.3 \mathrm{kN}$ were observed respectively for Condition 8 (2900 rpm and $5.8 \mathrm{~s})$ and Condition 9. All friction spot welds investigated in this work presented higher average ULSS in comparison to similar welds produced by resistance spot welding (RSW). ${ }^{28)}$ Nevertheless, current average performance of $10 \mathrm{kN}$ for AA 2024-T3 alloy friction spot welds are still bellow the desired strength observed for $9 \mathrm{~mm}$ diameter riveted joints $\left(19 \mathrm{kN}^{29)}\right)$. This is an indication that the FSpW of AA 2024-T3 alloy should be further optimized on one hand if riveting substitution is aspired; on the other hand FSpW could directly substitute RSW of $2 \mathrm{~mm}$ thick plates AA 2024-T3 alloy, considering that its current average ULSS is two times higher.

\section{Conclusions}

The following conclusions were driven from the current analysis of the full factorial design results for AA 2024-T3 alloy spot welds:

(1) The microstructure of the friction spot welds displayed typical metallurgical features observed in other materials welded by FSpW. The welded area is mainly composed of very fine dynamically recrystallized grains in the stir zone as a result of high shear rate and process temperatures (see Section 3.1).

(2) Lap shear testing specimens investigated in this work presented two types of failure mechanisms: "through the weld" fracture and "plug pullout with back plug" fracture. While former mechanism is usually associated with catastrophic brittle failure, the later is related to ductile failure. Both mechanisms resulted in high ULSS. Nevertheless joints failing through "plug pullout with back plug" mechanism presented higher fracture toughness (higher ductility) than joints failing by "through the weld fracture.

(3) The generated $3^{2}$ full factorial model resulted in a high level of statistical confidence for the investigated response ULSS (low $p$-values, high $T$-values and good coefficient of correlation). Although both first order factors $(R S$ and $J T)$ and the second order interaction $R S^{*} J T$ influence the behavior of the ULSS, $R S$ does not substantially changes the ULSS; JT and the $R S^{*} J T$ interaction are the most important factors affecting the joint strength of the specimens tested in this welding parameters range.

(4) The analysis of the main effect and interaction plots of the designed model indicated that increases in $R S$ will slightly increase ULSS while $J T$ will improve this response within $4.8 \mathrm{~s}$ to $5.8 \mathrm{~s}$, and depreciate it at some extent at $6.8 \mathrm{~s}$. Furthermore, $J T$ does not strongly interact with $R S$ within the range of $R S$ varying from 1900 to $2400 \mathrm{rpm}$ (curves follow a parallel pattern). This is not true for the joints produced with the highest $R S$ of $2900 \mathrm{rpm}$, where curve deviates from the standard behavior. At the lowest $J T$ ( $4.8 \mathrm{~s})$, increasing $R S$ will lead to stronger joints due to the elevation in thermal energy generation, causing the enlargement of the welded area. Nevertheless at the highest $J T$ (6.8 s), where heating efficiency is already elevate, increases in $R S$ will depreciate the frictional regime due to an increase in the temperature of the plasticized metal. Material viscosity and frictional performance will be reduced due to tool slippage. As a consequence less thermal energy is produced during the welding resulting in smaller welded areas and reduction in the ULSS.

(5) Stronger joints with lower standard deviation were produced when welding with intermediate $J T(5.8 \mathrm{~s})$ and $R S(2400 \mathrm{rpm})$.

\section{Acknowledgments}

The authors would like to acknowledge the financial support provided by Helmholtz Association, Germany. 


\section{REFERENCES}

1) C. Schilling and J. F. dos Santos: International Patent WO/2001/ 036144, May 2005.

2) A. M. Silva, M. A. D. Tier, T. S. Rosendo, F. D. Ramos, C. C. P. Mazzaferro, J. A. E. Mazzaferro, L. A. Bergmann, T. R. Strohaecker and J. F. dos Santos: Buletin de Informare Documentara (I.S.I.M.) 3 (2007) 36-44.

3) T. S. Rosendo, A. M. Silva, M. A. D. Tier, F. D. Ramos, J. A. E. Mazzaferro, C. C. P. Mazzaferro, J. F. dos Santos and T. R. Strohaecker: Proc. XXXIII CONSOLDA-Congresso Nacional de Soldagem, Caxias do Sul, Brazil, (October 2007).

4) J. W. Arbegast: Proc. Int. Seminar on Friction based Spot Welding Processes, Geesthacht, Germany, (March 2007).

5) J. Varis: J. Mater. Sci. Tech. 172 (2006) 130-138.

6) L. Han, K. W. Young, A. Chrysantou and J. M. O'Sullivan: Mater. Design 27 (2006) 1108-1113.

7) Y. S. Yang and S. H. Lee: J. Mater. Sci. Technol. 94 (1999) 151156.

8) Y. Zhou, S. Fukomoto, J. Peng, C. Ji and L. Brown: J. Mater. Sci. Technol. 20 (2004) 1226-1232.

9) A. M. Silva, M. A. D. Tier, T. S. Rosendo, F. D. Ramos, J. A. E. Mazzaferro, C. C. P. Mazzaferro, S. T. R. Strohaecker and J. F. dos Santos: SAE Technical Paper Series, 7ATC-103 (2007).

10) K. Y. Benyounis and A. G. Olabi: Adv. Eng. Software 39 (2008) 483496.

11) G. Casalino: J. Mater. Process. Technol. 191 (2007) 106-110.

12) A. G. Olabi, G. Casalino, K. Y. Benyounis and A. Rotondo: Mater. Design 28 (2007) 2295-2302.

13) A. K. Lakshminarayanan and V. Balasubramanian: Trans. Non-ferrous Met. Soc. China 18 (2008) 548-554.

14) F. Hunt, H. Badarinarayan and K. Okamoto: SAE Technical Paper Series, 2006-01-0970 (2006)
15) C. Oberembt, C. Allen, W. Arbegast and A. Patnaik: Proc. TMS 2007 Annual Conference of The Minerals, Metals \& Materials Society, Friction Stir Welding and Processing IV (2007) pp. 359-368.

16) ASM International: Handbook of Aluminium \& Aluminium Alloys 3rd ed., USA (1996) p. 59.

17) ASM International: Handbook of Aluminium \& Aluminium Alloys 3rd ed., USA (1996) pp. 73-74.

18) European Standard: EN DIN 895-Qualitätssicherung in der Schweißtechnik, Querzugversuch, Germany, (1995).

19) German Standard: DIN EN ISO 14273, Specimen dimensions and procedure for shear testing resistance spot, seam and embossed projection welds, Germany, (2000).

20) A. P. C. Camillo: Estudo das propriedades mecânicas e de resistência a corrosão da solda ponto por fricção (FSpW) em ligas de aluminio, Internship Report, (Federal University of Sao Carlos (UFSCar), Brazil, June 2009).

21) M. Tier, T. S. Rosendo, C. A. W. Olea, C. C. P. Mazzaferro, F. D. Ramos, M. Bayer and J. F. dos Santos: Proc. 7th Int. Symp. on Friction Stir Welding, Awaji Island, Japan, (May 2008).

22) T. S. Rosendo: PhD-thesis, (Federal University of Rio Grande do Sul (UFRGS), October 2009).

23) S. T. Amancio-Filho, S. Sheikhi, J. F. dos Santos and C. Bolfarin: J. Mater. Process. Technol. 206 (2008) 132-142.

24) C. D. Allen and W. J. Abergast: Proc. SAE International Congress, Detroit, MI, (2005).

25) P. Su, A. Gerlich, T. H. North and G. J. Bendzsak: Sci. Tech. Weld. Joining 11 (2006) 163-169.

26) H. B. Schmidt and J. H. Hattel: Scr. Mater. 58 (2008) 332-337.

27) A. P. C. Camillo: Internal Report, (GKSS Research Center, Geesthacht Germany, January 2009).

28) Society of Automotive Engineering: Standard SAE AMS-W-6858Welding: Resistance, Spot and Seam, USA, (2000).

29) MIL Military Handbook: MIL-HDBK-5H-Metallic Materials and Elements for Aerospace Vehicle Structures, Ch. 8 (1998) pp. 8-11. 